EMBRYARIDDLE
Aeronautical University

SCHOLARLY COMMONS

\section{International Journal of Aviation,} Aeronautics, and Aerospace

\title{
Computational Study of Flow Interactions over a Close Coupled Canard-Wing on Fighter
}

\author{
Setyawan Bekti Wibowo \\ Universitas Gadjah Mada, Indonesia, setyawanbw@ugm.ac.id \\ Sutrisno Sutrisno \\ Universitas Gadjah Mada, sutrisno@ugm.ac.id \\ Tri Agung Rohmat \\ Universitas Gadjah Mada, triagung_rohmat@ugm.ac.id
}

Follow this and additional works at: https://commons.erau.edu/ijaaa

Part of the Aerodynamics and Fluid Mechanics Commons, and the Computer-Aided Engineering and Design Commons

\section{Scholarly Commons Citation}

Wibowo, S. B., Sutrisno, S., \& Rohmat, T. A. (2019). Computational Study of Flow Interactions over a Close Coupled Canard-Wing on Fighter. International Journal of Aviation, Aeronautics, and Aerospace, 6(1). https://doi.org/10.15394/ijaaa.2019.1306

This Article is brought to you for free and open access by the Journals at Scholarly Commons. It has been accepted for inclusion in International Journal of Aviation, Aeronautics, and Aerospace by an authorized administrator of Scholarly Commons. For more information, please contact commons@erau.edu. 


\section{Introduction}

Aircraft technology is always evolving to improve efficiency and flight ability. One of the improvement efforts is by modifying the flow along the fuselage by adding a canard to the front of the aircraft wing. Canard is a part of an airplane that functions as a stabilizer or elevator and is placed in front of the main wing (Crane, 2012). The addition of a pair of canard wings will increase the lift force while delaying the occurrence of a stall at high angles. On the wing form of a fighter wing in the form of a delta wing will produce a rolled-up vortex that will produce lift force on the wing of the aircraft.

The delta wing configuration as the basic shape of the wing and canard on a fighter aircraft will produce the rolled-up vortex that will add the lifting force (Polhamus, 1966; Polhamus \& Polhamus, 1966). Rolled-up vortex has an area in the center which has very high velocity and low pressure as a lifting force called the vortex core. On delta aircraft, this vortex core is the place where the concentration of lift is formed. The addition of forewings such as canard or Leading Edge Extension (LEX) also produces a strong vortex core leading backward and influencing airflow along the main wing.

The existence of a very complex flow interaction from the vortex which is formed from the canard to the air flow in the main wing makes the characteristics of the plane change; this condition is very important to be observed. Several flow phenomena that occur, such as rolled-up vortex, vortex core, vortex breakdown, flow separation, and vortex merging require special analysis for further observations to uncover airflow phenomena in fighter aircraft to be able to improve the ability of aircraft.

Several previous studies have conducted studies on the use of canard in aircraft which in general can illustrate an increase in flight performance. Most of this research takes the subsonic velocity area to characterize canard use on aircraft. Several studies demonstrate the significant increase in lift (Ali, Kuntjoro, \& Wisnoe, 2012, 2013; Anand, \& Kulkarni, 2014; Davari, Hadidoolabi, Soltani, \& Izadkhah, 2015; Desharnais, 2014; Jindeog, Tahwan, \& Bongzoo, 2002; Lopes \& da Mota Girardi, 2005; Manshadi, Sharafi, \& Soltani, 2012; Nasir, Kuntjoro, \& Wisnoe, 2014; Reduan et al., 2010; Rizzi, 2011; Wibowo \& Basuki, 2014). The total lift force of the aircraft is produced together by the main wing and canard. Therefore, this increase in lift can increase the efficiency of aircraft or wing loading to be smaller.

Aerodynamic force analysis will show an increase in the ability of aerodynamic characters such as an increase in lift force and the ability to withstand the occurrence of the stall. Analysis of this phenomenon needs to be further supported 
by a study of airflow and vortex dynamics that occur. The addition of a canard on the front of the wing will positively affect the airflow that will pass through the main wing. Flow interference that occurs due to the vortex produced by the canard will be used to characterize the flow in the main wing so that the analysis of the phenomenon of flow patterns that occur becomes very important. The position of the canard towards the main wing will significantly influence the pattern of flow interactions that arise so that the flying character and vortex dynamics that occur will also change. Analysis of vortex dynamics in canard-main wing pairs needs to be done to find the optimal configuration of a fighter aircraft. To analyze vortex phenomena and their interaction on the main canard-wing pair, the use of visualization techniques is very instrumental in uncovering the phenomenon. Visualization using the Computational Fluid Dynamics (CFD) method will provide complete results both quantitatively and qualitatively. The simulation results obtained need to be validated on the experimental results to ensure good simulation results. Also, it is also necessary to first conduct a computational feasibility study including the study of mesh independence and convergence. The use of the experimental method using a water tunnel will provide good results to get detailed visualization results and aerodynamic forces that occur.

The use of water tunnels (WaTu) has long been used to see the visualization of flow testing on moving objects or fluid flow such as fighter aircraft. The method of water tunnel to understand the flow dynamics that occur in aircraft is very visible and is an advantage compared to the wind tunnel system (Cai, Cui, \& Tsai, 2007; Cobleigh \& Delfrate, 1994; Frate, 1995; Frink, Lamar, Lamar, Cowley, \& Gouws, 1980; Jaroszewicz, Stachow, Sibilski, \& Zyluk, 2011; Kerho, 2007; Kim, 1991; Sandlin \& Ramirez, 1991; Sutrisno et al., 2018; Thompson, 1990; Wibowo, Sutrisno, \& Rohmat, 2018). Water tunnels are very powerful for researching fighter planes such as the joint strike fighter, missiles, unmanned aerial vehicles, UAVs, ships, and submarines. In many ways, water tunnels are a better choice than testing models in low-speed wind tunnels. For testing visualization - the use of flow with coloring, water is a test media that is far better than air (Erickson, 1982; Erm \& Ol, 2012; Sohn, Lee, \& Chang, 2004; Sohn, Lee, \& Chang, 2008).

\section{Materials and Methods}

In this research, an aircraft model with a delta wing base was created with a swap angle value of $60^{\circ}$ as shown in Figure 1. Configuring canard additions is arranged in horizontal and vertical directions. Canard position change based on changes in the horizontal direction within each $1 / 4$ chord length canard, while changes in the vertical direction are adjusted according to canard thickness.

Experimental testing using a water tunnel is carried out as a comparison of flow analysis to the visualization test and lift force for the basic configuration of 
the shape of the aircraft. The configuration of the water tunnel testing and parameters refers to Wibowo et al. (2018) with a flow rate of $0.1-0.23 \mathrm{~m} / \mathrm{s}$ as shown in Figure 2. The experimental results are used to obtain visualization by injecting ink and calculating the lift coefficient $(\mathrm{Cl})$ by measuring the lift force occurs using load balance water tunnel (Firmansyah, Wibowo, \& Mareta, 2017). Injection ink is used to identify the occurrence of vortex cores in aircraft models. The test is done by adjusting the angle of attack from $\alpha=0^{0}$ to $60^{\circ}$ with step $10^{\circ}$.

In the simulation using the Computational Fluid Dynamics (CFD) method, the computational model is made symmetrically with size referring to the water tunnel experiment. The size of the domain is made based on several references so that the inlet, outlet, and wall will not affect the flow in the simulation model. The size and configuration of the computational domain are shown in Figure 3.
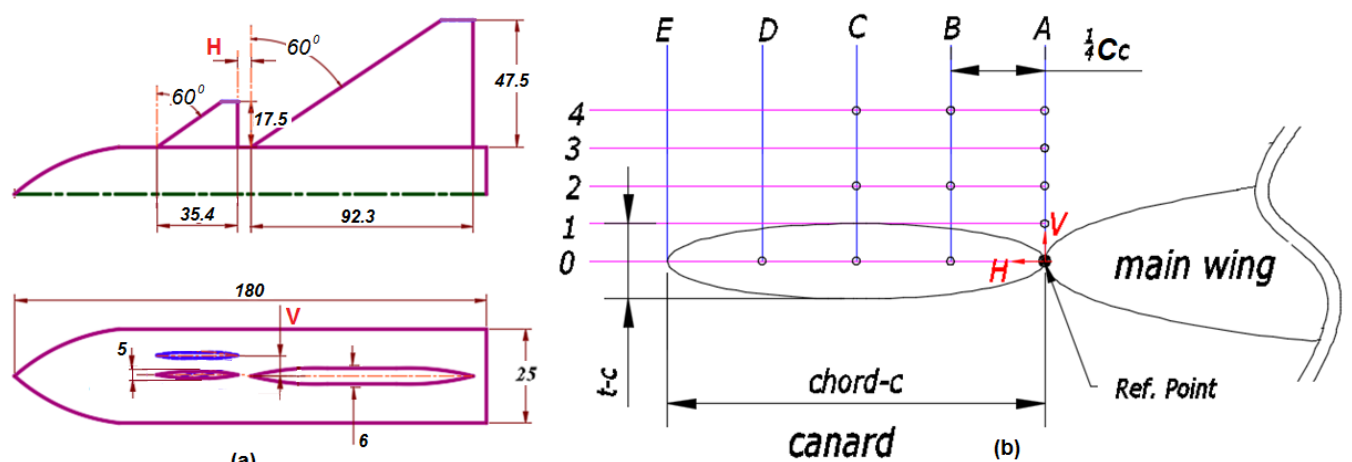

(a)

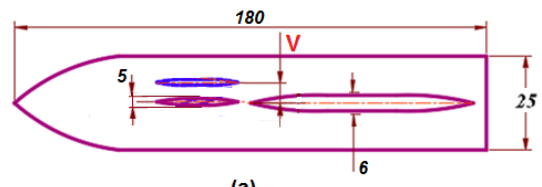

(b)

Figure 1. Model configuration and variation in canard position changes. 


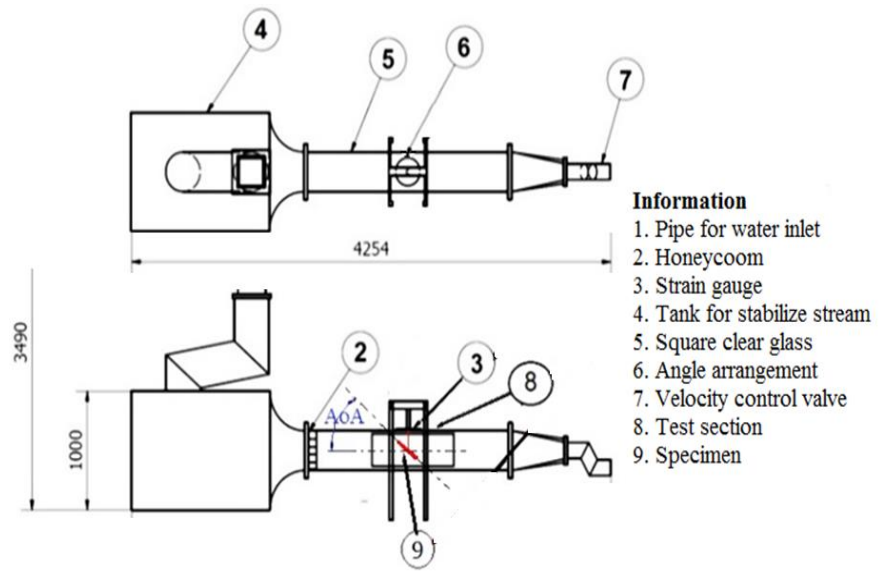

(a) Water tunnel facility test

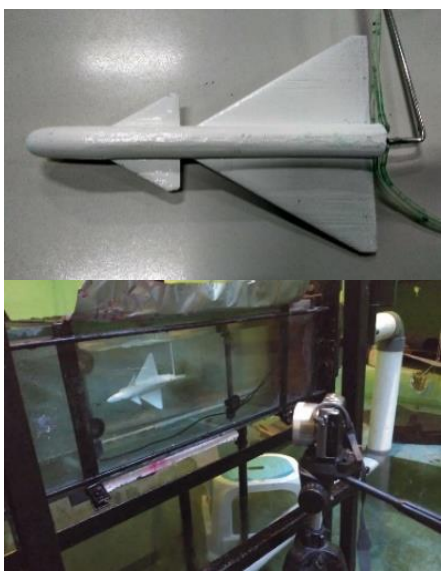

(b) Specimens configuration

Figure 2. Water tunnel testing and specimen configuration. 


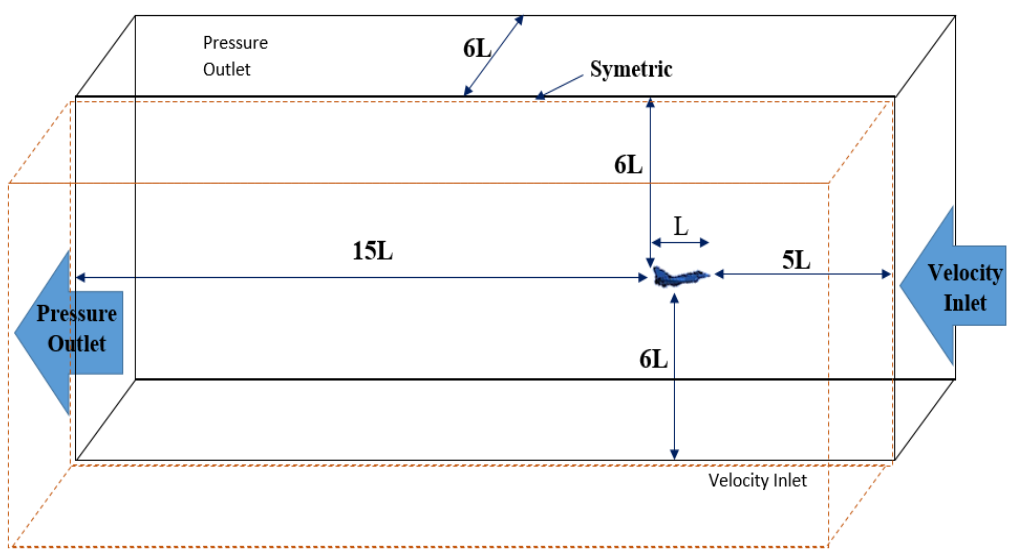

(a) computational domain

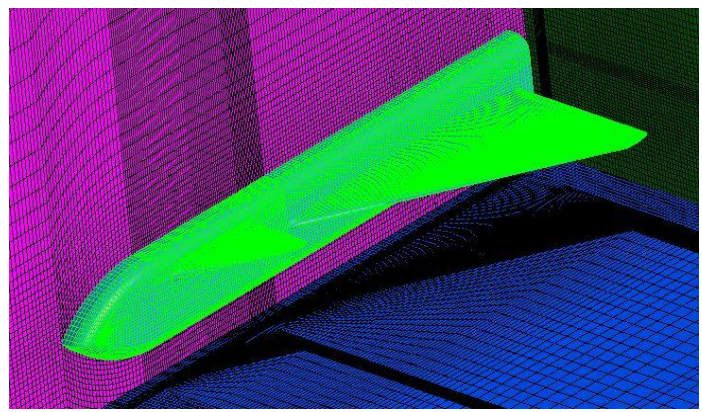

(b) Mesh model isometric view

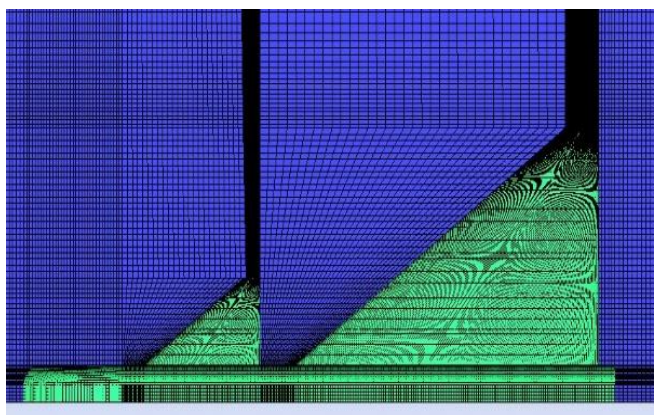

(c) Mesh model top view

Figure 3. Domain and computational mesh configuration.

The configuration of the computational cells uses the H-structured mesh type. Mesh independency study needs to be done to determine the smallest mesh size and number of the required mesh so that the optimal simulation results are obtained. The mesh independency study based on a previous study (Wibowo, Sutrisno, \& Rohmat, in press). The essential factor to get a good rolled-up vortex and vortex core is in determining the smallest cell. The smallest cell is obtained from the use of dimensionless wall distance $(y+)$ with $y+$ value taken for $y+=1$. As for the results of the mesh independency study, the number of cells with convergence values on the qualitative value of $\mathrm{Cl}$ is 5 million cells. In this study used 5.4 million cells with the smallest cell size of $0.00061 \mathrm{~m}$.

Identification of the occurrence of rolled-up vortex phenomena and the vortex breakdown is essential in revealing the characteristics of fighter aircraft. To obtain computational completion, the use of turbulence models considerably influences the vortex pattern that occurs. Based on previous research, the use of the D-DES 
turbulence model was able to detect vortex phenomena very well (Wibowo et al., 2018). For this study, the D-DES method was used for the turbulence equation.

\section{Results}

The results of the study are presented in the lift coefficient $(\mathrm{Cl})$ value from the CFD compared to the results of the water tunnel experiment as shown in Figure 4. In the picture can be seen the effect of increasing the lifting force on the addition of canard in all positions. Overall, the addition of a canard will increase the lift coefficient of the aircraft model by up to $12 \%$. In the low angle of attack (AoA) (under $20^{\circ}$ ) the $\mathrm{Cl}$ value for each model has the same value. After AoA is higher than $20^{\circ}$, there is a difference in lift coefficient value. In aircraft models without using canard, the $\mathrm{Cl}$ value increases up to AoA $35^{\circ}$ and after that decreases the value of $\mathrm{Cl}$. The picture also shows that the simulation results have good similarity to the $\mathrm{Cl}$ value compared to the experimental results using a water tunnel (WaTu).

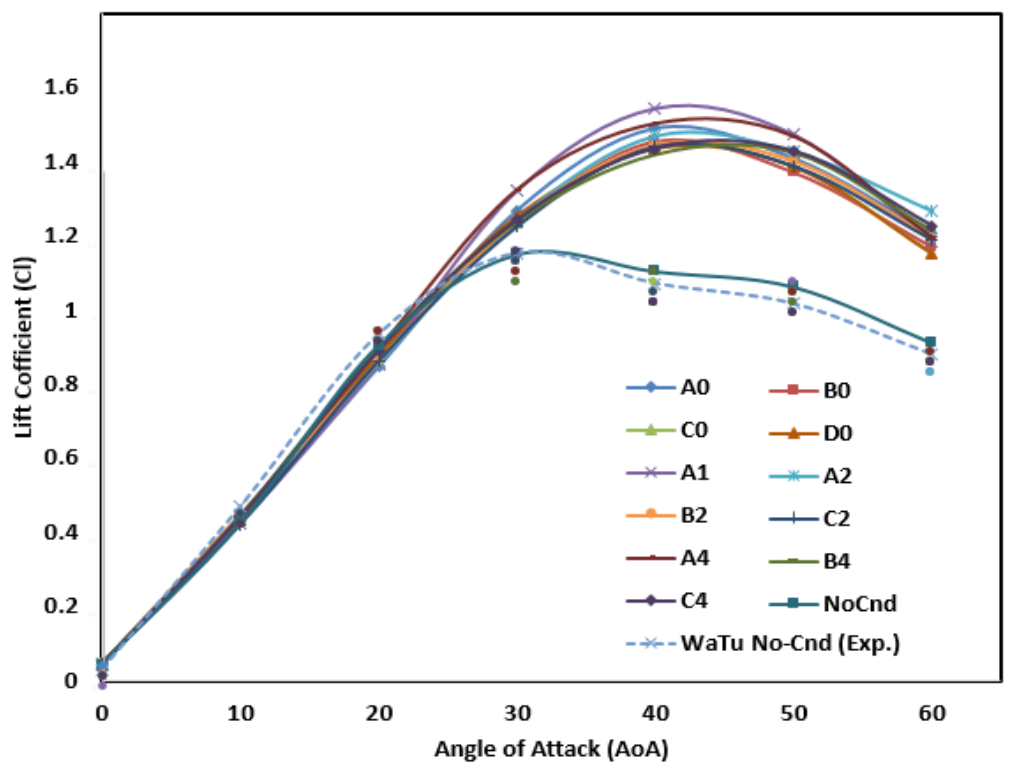

Figure 4. Lifting coefficient $(\mathrm{Cl})$ on canard position variations against AoA from the CFD and experiment results (no-canard).

In configurations with canard additions, the lift coefficient still increases to $\mathrm{Cl}$ maximum for AoA over $40^{\circ}$. The increase in AoA at maximum $\mathrm{Cl}$ in the canard configuration shows that there is still a lift force compared to conditions without canard. The rise in AoA at maximum $\mathrm{Cl}$ also indicates that the stall condition is delayed more at higher AoA. Almost all canard configuration configurations used can delay the occurrence of stall, but in detail, there are differences in the 
characteristics of the $\mathrm{Cl}$ value for each configuration. To see in detail the changes that are at a higher angle, then at $30^{\circ}-50^{\circ} \mathrm{AoA}$, detailed observation of the lift coefficient value is carried out.

Figure 5 shows the difference in lift coefficient in detail at $30^{\circ}-50^{\circ}$ AoA for coplanar/horizontal and vertical canard position changes on the main wing. Figure 5a shows the difference in $\mathrm{Cl}$ values for coplanar/horizontal canard position. In the coplanar position, the canard position approaching the main wing (case A0) will produce the highest $\mathrm{Cl}$ value. This condition causes the AoA value at maximum $\mathrm{Cl}$ to shift at a higher angle of attack so that this configuration will be better able to maintain lift. Figure $5 \mathrm{~b}$ shows the lift coefficient value in AoA detail with vertical canard position variation. It can be seen that from the parallel position to the main wing then shifts upwards causing a slight increase in lift. However, increasing position does not always increase $\mathrm{Cl}$, in vertical distance configurations $1 / 2 t_{c}$ and $t_{c}$ (cases A1 and A2) show the highest increase in $\mathrm{Cl}$ value, and after that, it decreases again.

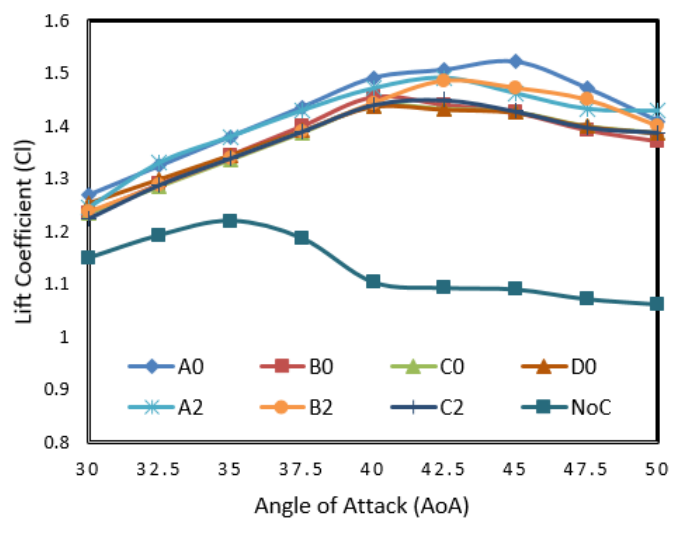

(a) coplanar position

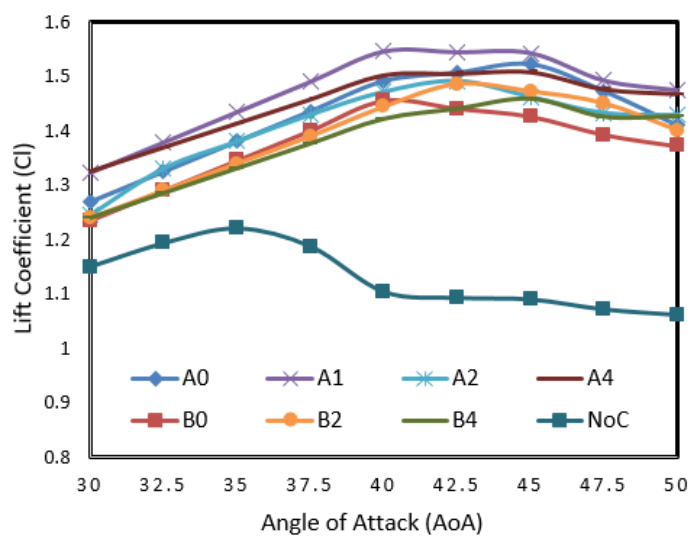

(b) vertical position

Figure 5. $\mathrm{Cl}$ value in detail at $\mathrm{AoA} 30^{\circ}$ and $40^{\circ}$ on canard position variations.

The results of the computational model need to be validated with the results of the water tunnel experiment. Experiments using the GAMA water tunnel test facility that has been configured refer to previous studies (Wibowo et al., 2018). Validation was carried out by measuring $\mathrm{Cl}$ and observing the core vortex phenomenon and the occurrence of vortex damage along the main wing in noncanard models, then comparing the results between simulation and experimental results both qualitatively ( $\mathrm{Cl}$ value) and quantitative (vortex visualization). Figure 4 shows the good similarity for the $\mathrm{Cl}$ value, while the results of visualization of the vortex core and the position of vortex damage can be seen in Figure 6 with good similarities. 


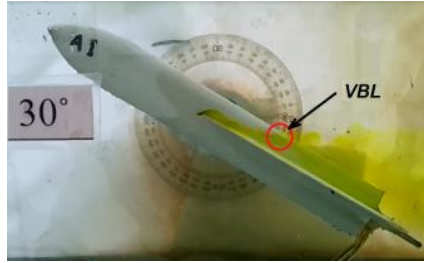

(a) Side view

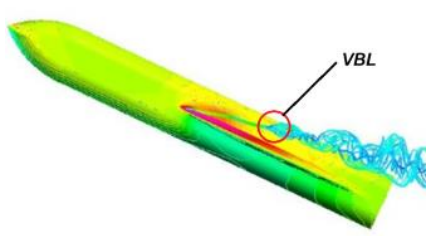

(b) Top view

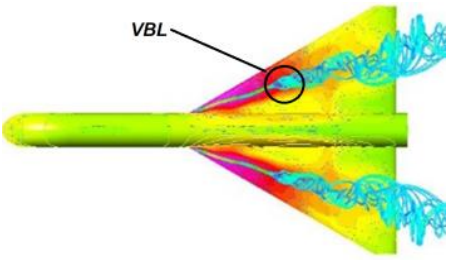

(c) visualization from visualization with CFD visualization with CFD water tunnel (experiment)

Figure 6. Visualization of vortex core path-line and vortex breakdown location (VBL) at no-canard configuration

Flow characteristics of the fighter model were analyzed using CFD by observing vortex core formation, contour velocity distribution, and flow pathline along the canard and main wing as shown in Figure 7. From the airflow character, it can be determined the formation of the vortex core, flow interactions that occur or vortex damage. 


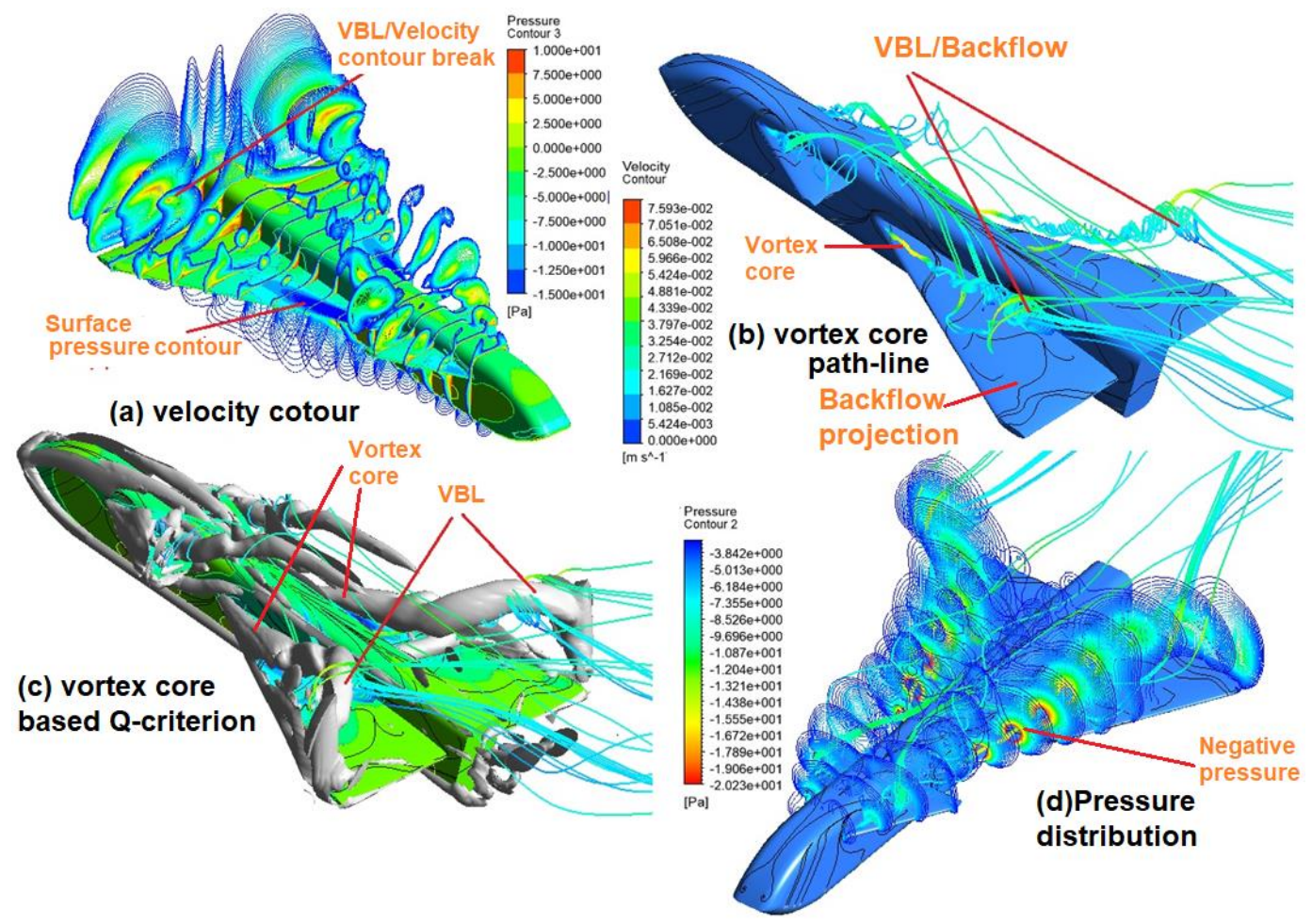

Figure 7. Visualization of velocity contours and the development of vortex cores based on Q-criterion.

The vortex core is shown through visualization of vortex core based on Qcriteria, direction, and value of flow vortex speed, and form of the velocity distribution. While vortex breakdown is shown by sudden vortex core enlargement, velocity contour breakage, and backflow. The kind of flow interaction is reflected in the direction of flow and velocity distribution above the main wing.

Changes in canard position in both horizontal and vertical directions cause differentiation of the lift coefficient force $(\mathrm{Cl})$ This condition is affected by the formation of flow interactions from the canard. Figure 8 and Figure 9 show the visualization of the flow of the canard and the main wing in forming rolled-up vortex using CFD technique at AoAs 300 and 500. In the figure also shows how the flow of each flow interacts in the formation of a vortex core as a source of lift force on the wing. In the higher AoA (500), it is seen that the location of vortex breakdown progresses closer to the leading edge. In the comparison of canard locations horizontally (Cases A0, B0, C0, and D0 as well as in cases A2, C2, and B2) shows the vortex core trajectory going up above the main wing, causing the flow interaction to decrease. 


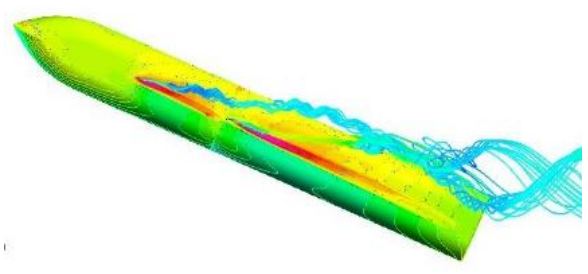

(a) A0 case

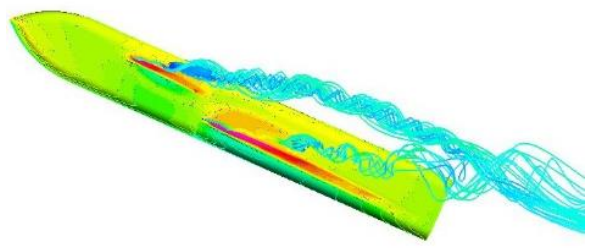

(b) A4 case

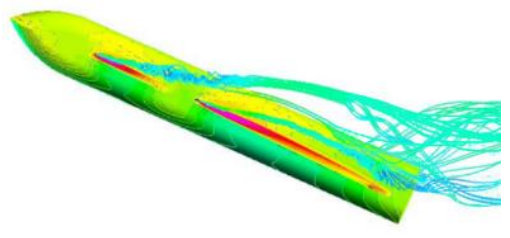

(c) $\mathrm{C} 0$ case

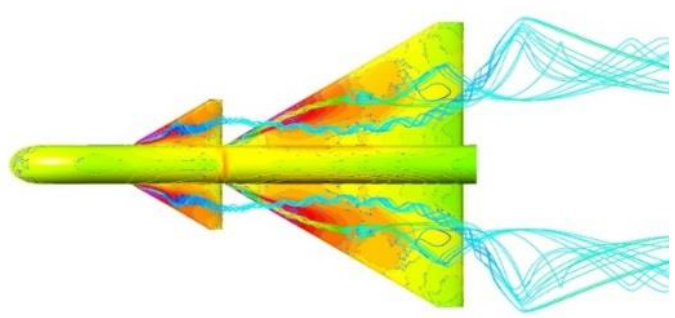

(d) A0 case

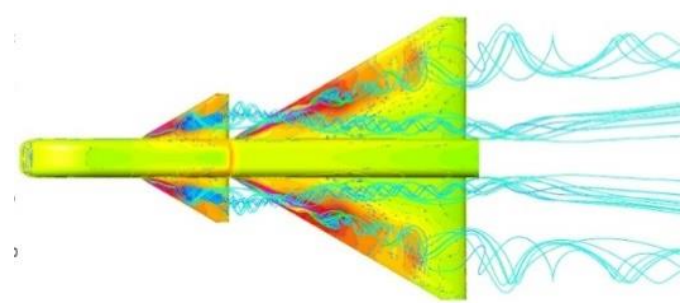

(e) A4 case

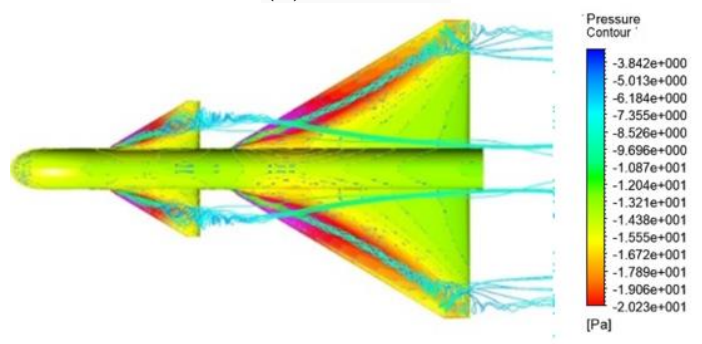

(f) $\mathrm{C} 0$ case

Figure 8. Visualization of flow interactions from a side and top view for canard position variations at $\mathrm{AoA} 30^{\circ}$. 


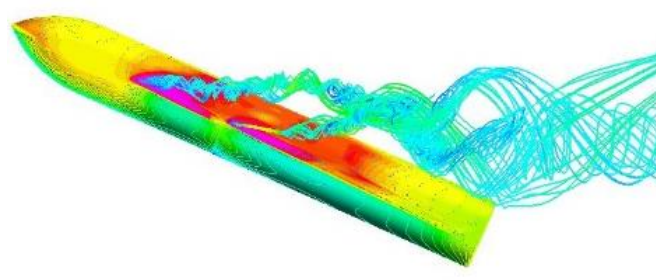

(a) A0 case

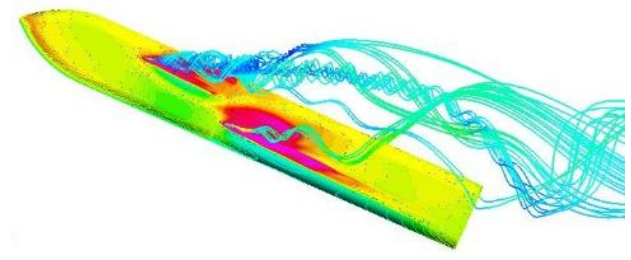

(b) A4 case

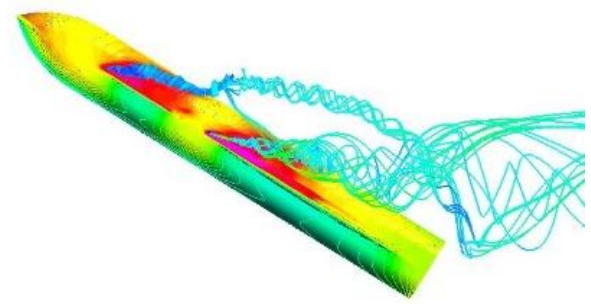

(c) C0 case

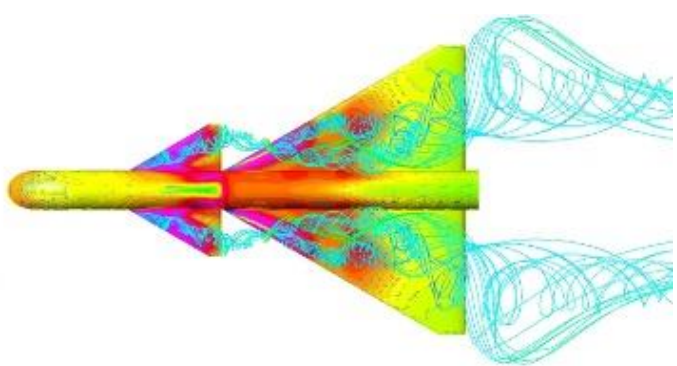

(d) A0 case

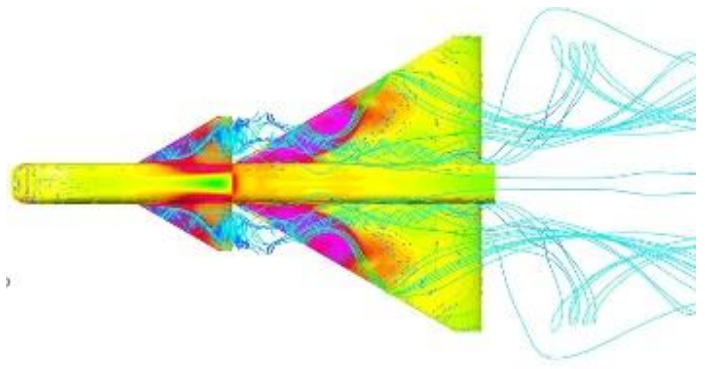

(e) A4 case

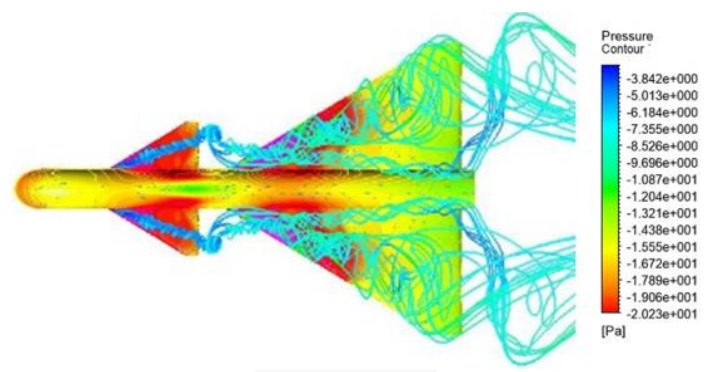

(f) $\mathrm{C} 0$ case

Figure 9. Visualization of flow interactions from a side and top view for canard position variations at $\mathrm{AoA} 50^{\circ}$.

Figure 10 shows in detail the vortex core trajectory on the main wing from the side and top views for the AoA $30^{\circ}$. At low attack angles $\left(\mathrm{AoA}<30^{\circ}\right)$, the canard position configuration that is parallel and close to the main wing (cases A0, A1, and B0) results in a low vortex core path as shown in Figure 10a. However, the condition of the canard position farther away from the main wing causes the vortex's core trajectory to rise upward and has the effect of reducing the formation of lift force on the aircraft wing. 


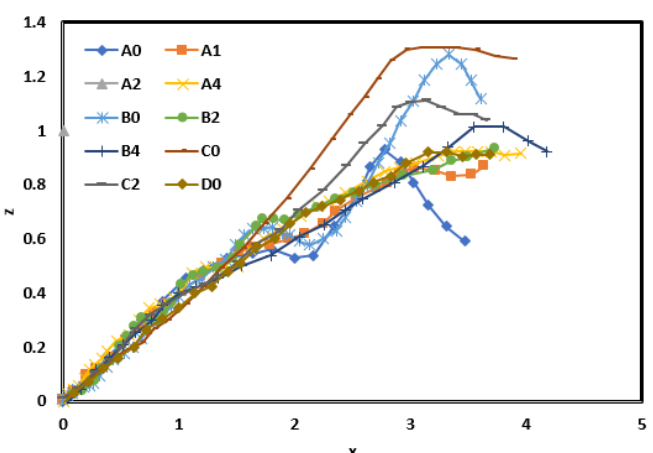

(a) The height of the vortex core trajectory, AoA $30^{\circ}$

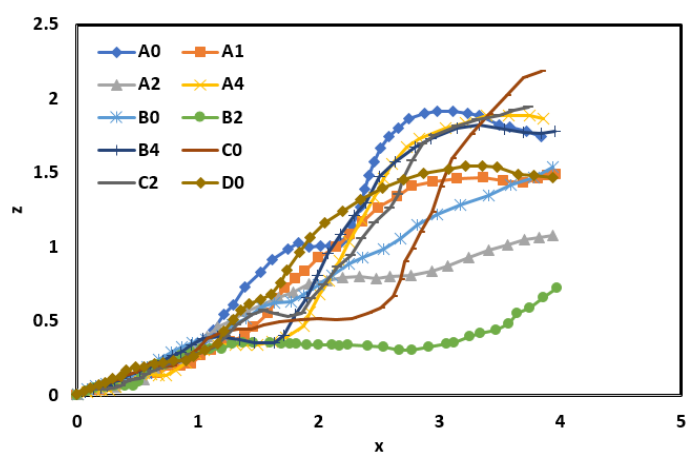

(c) The height of the vortex core trajectory, AoA $50^{0}$

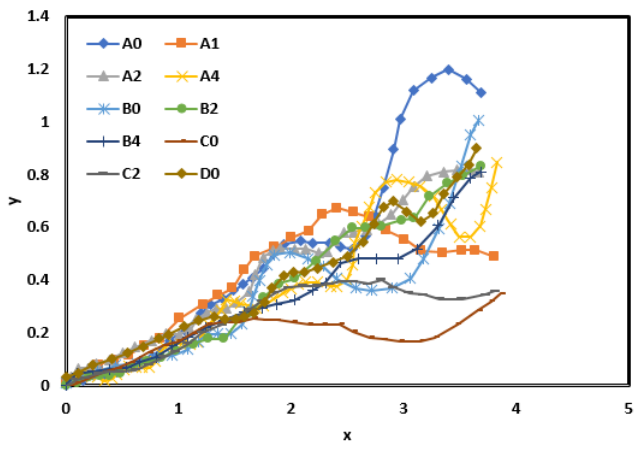

(b) Vortex core trajectory across the wing, AoA $30^{\circ}$

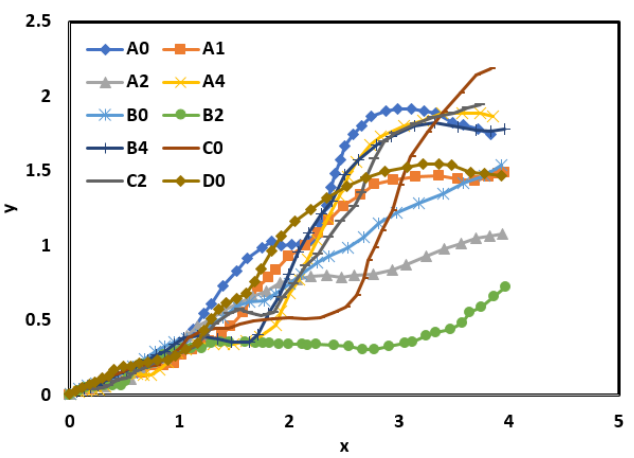

(d) Vortex core trajectory across the wing, AoA $50^{\circ}$

Figure 10. Vortex core trajectory in the vertical and transverse direction above the main wing for variations in canard position at $\mathrm{AoA} 30^{\circ}$ and $50^{\circ}$.

Figure 10b shows the position of the vortex core in a horizontal direction above the wing of the plane. In the canard position configuration approaching the main wing will cause the tendency of the trajectory to widen on near the leading edge of the main wing (Cases A0 and A1). While in the canard position that is far from the main wing will produce a trajectory that tends to approach the fuselage. Figure 10.c and 10.d show the details of the vortex core trajectory in the main wing for AoA $50^{\circ}$. At a high angle of attack (AoA $>40^{\circ}$ ). With the higher AoA, the vortex core also changes both the canard and the main wing. Figure 10.c shows the height of the formation of a vortex core on the main wing in the vertical direction. The vortex core in the configuration for the canard adjacent to the main wing (case A0) results in a higher trajectory compared to the configuration of the further canard position. The farthest canard position still produces the highest trajectory. The lowest path occurs in B2 and $\mathrm{C} 0$ position configurations. In high AoA conditions for the canard 
location configuration which is near the main wing causes airflow to be obstructed on the main wing producing vortex instability and causing the vortex core to be breakdown quickly. In AoA, the high canard position in front of and above the main wing (cases B2 and C2) gives flow space, so that vortex interaction is better.

While in Figure 10.d shows the vortex core trajectory horizontally at the angle of attack $50^{\circ}$. In the high angle of attack, the effect of horizontal trajectory also changes. In areas near the leading edge or the front area of the wing have a similar trajectory tendency up to 0.4 wing length. After this location, there is a different path because there has been a vortex core damage based on the visualization results in Figure 9.

Figure 11 shows a picture of the pressure distribution on the main wing surface for the location of the root mean chord (x / L) at $21 \%, 43 \%$ and $60 \%$ with AoA $30^{\circ}$, $40^{\circ}$, and $50^{\circ}$. The pressure distribution shows the pressure difference on the upper and lower surfaces on the wing section with a certain distance. From the different pressures that indicate the concentration of the lifting force that occurs. At AoA $30^{\circ}$ conditions and close to the leading edge ( $\mathrm{x} / \mathrm{L}=21 \%)$, it can be seen that the highest pressure on the wing surface occurs in the upper canard position (cases $\mathrm{A} 4$, B4, and B2).

The more to the rear of the wing, the pressure distribution of each canard configuration also changes. At $\mathrm{x} / \mathrm{L}=43 \%$, the pressure difference in the canard configuration B2 case remains large followed by the $\mathrm{C} 0$ case, while the A4 and B4 cases start to shrink. Similarly, on the back of the wing ( $\mathrm{x} / \mathrm{L}=60 \%)$, the difference in surface pressure is still seen in the cases $\mathrm{C} 0$ and B2. The pressure difference in other canard case configurations shows that in the upper part of the wing it has begun to spread evenly, this indicates that it has already started to diminish or the loss of vortex core influences. While in the case without canard, this condition has begun to fluctuate in different pressures along the plane of the wing, this indicates the start of a high vorticity intensity or damage to the vortex core.

At an increase of AoA $40^{\circ}$ and $\mathrm{x} / \mathrm{L}=21 \%$, the greatest difference in wing surface pressure is seen in the cases of B2 A4, and B4 followed in other cases. In a more backward location $\mathrm{x} / \mathrm{L}=43 \%$ there is a decrease in pressure difference in the case of B2, A4, and B4 approaching the same value, while for other canard configurations the pressure difference above the wing is smaller. While in the case without canard the pressure difference above the wing has fluctuated which indicates that the vortex breakdown has occurred. Next at the back of the location at $\mathrm{x} / \mathrm{L}=60 \%$, there was a decrease in the whole case except in the case of $\mathrm{C} 0$ it persisted. For the case of A0, A1 and without canard it has fluctuated pressure above the wing. 


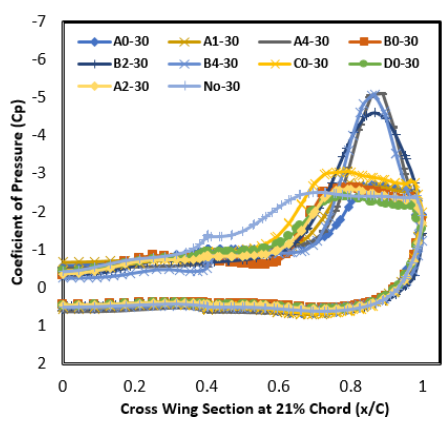

(a) $21 \%$ mac wing AoA $30^{\circ}$

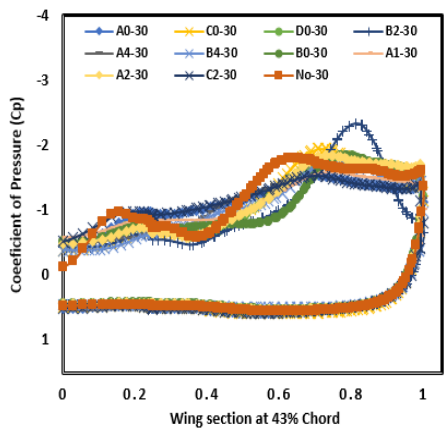

(d) $43 \%$ mac wing AoA $30^{0}$

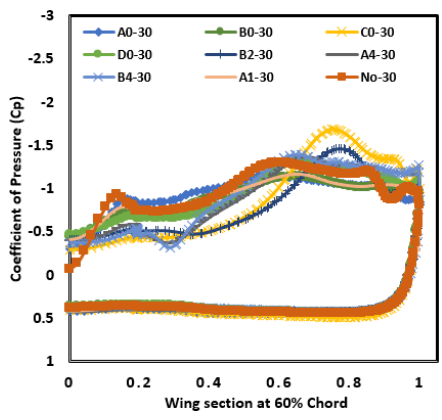

(g) $60 \%$ mac wing AoA $30^{0}$

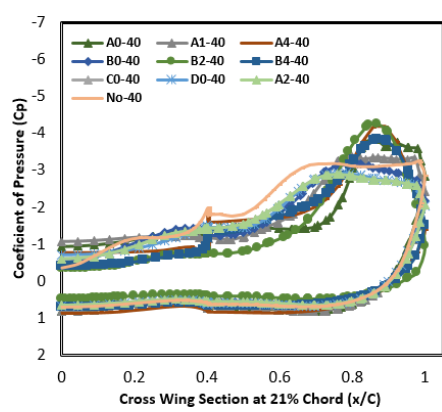

(b) $21 \%$ mac wing AoA $40^{0}$

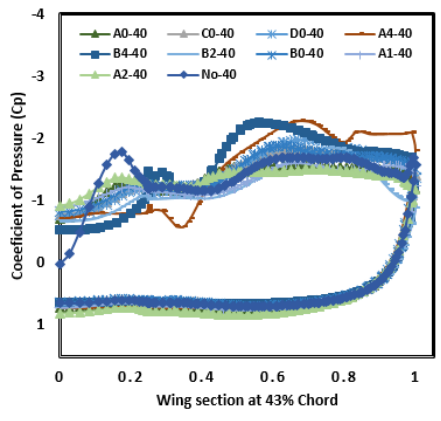

(e) $43 \%$ mac wing AoA $40^{0}$

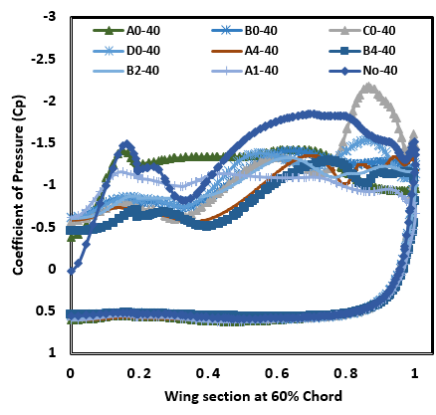

(h) $60 \%$ mac wing AoA $40^{0}$

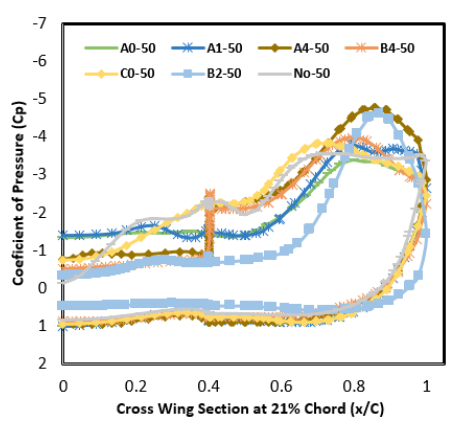

(c) $21 \%$ mac wing AoA $50^{0}$

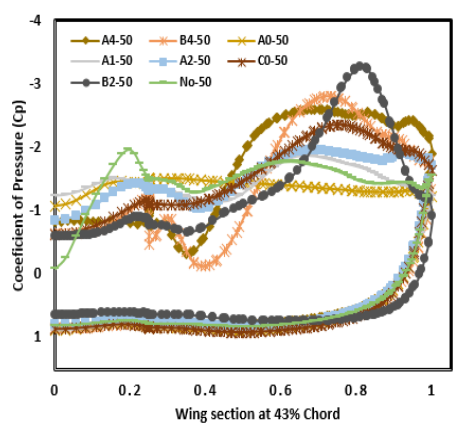

(f) $43 \%$ mac wing AoA $50^{0}$

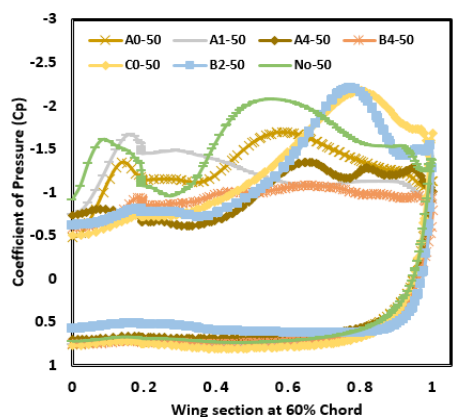

(i) $60 \%$ mac wing AoA $50^{0}$

Figure 11. Pressure distribution for the wings locations $21 \%, 43 \%$, and $60 \%$ mean aerodynamics chords (mac) with AoA $30^{\circ}, 40^{\circ}$, and $50^{\circ}$.

At the $\mathrm{AoA} 50^{\circ}$ for the position on the front $\mathrm{x} / \mathrm{L}=21 \%$ the biggest pressure difference is seen in the case of A4 and B2, followed by another case canard 
configuration. In the no-canard configuration, it has shown fluctuating symptoms, thus indicating the occurrence of vortex breakdown. In a more backward location ( $\mathrm{x} / \mathrm{L}=43 \%$ ), the $\mathrm{B} 2$ case shows the pressure difference is still quite large, while the A4 and B4 cases have begun to decline followed by the $\mathrm{C} 0$ case. The other case configurations are seen starting the fluctuating phase of pressure. At the location of $\mathrm{x} / \mathrm{L}=60 \%$ configuration of the canard position which still shows the pressure difference on the wing surface is in the $\mathrm{B} 2$ case and $\mathrm{C} 0$, while in other cases it has experienced a fluctuating pressure which indicates a vortex breakdown.

\section{Discussion}

In the case of changes in canard position horizontally (Cases A0, B0, C0, and D0) each has a different characteristic interaction between canard vortex and wing vortex. Figure 8 shows the formation of vortex core path-lines from the canard for the changes of horizontal canard position from the side and upper side views. The vortex core formed from the canard will interact with the main wing vortex core and became merge. In the canard position closest to the main wing, flow interactions occur faster and closer above the main wing. The farther canard position causes the vortex core trajectory to move upwards, the interaction decreases and the vortex core's merging location retreats to the main wing.

Similarly, in the comparison of canard position horizontally (Cases A2, B2, and $\mathrm{C} 2$ ), the canard position closer to the main wing will result in greater interaction. The formation of a rolled-up vortex from the further canard position to the main wing will be easily lifted up, so the interaction effect becomes less. While the roll-up vortex formation from the canard with a closer position will remain in a low position above the main wing, this is seen in the cases A0, B0, A2, and B2. In lower canard vortex formation, the main wing flow is more maintained in a streamlined form and thus better flow stability. Flow stability makes the vortex core more stable and more difficult to breakdown. In other words, the lower the vortex flow from the canard above the main wing will delay vortex breakdown in the main wing.

Changes in the canard position vertically also produce differences in the vortex trajectory of the canard (Cases A0, A1, A2, and A4; and in the Cases B0, B2, and B4). In general, the increase in canard position causes the trajectory of the canard's vortex to rise above the main wing, thereby reducing interaction. However, the increase in flow height in the case of A1 is not significant in reducing flow interactions because the canard position is still low. This condition is shown in cases A0 and A1 which have no differences in location of the interaction of the flow between the canard's vortex and the main wing. While at a higher position than A1 (A2 and so on) the merging of the flow between vortices is more backward due to the reduction in flow interaction. 
The pressure distribution on the wing and fuselage surface can indicate the strength of the interaction between the canard's vortex and the main wing. The strength of vortex interaction will cause the rolled-vortex structure to expand on the outer side of the main wing (away from the fuselage wall). This condition causes the focus of lift to be on the wing of the plane as shown in Figure 8. The closer position of the vortex core to the fuselage causes the influence of negative pressure on the wall due to the pulling force of the vortex core generated by the aircraft body. In Figure 8 it can be seen that in the canard position which is far or too high towards the main wing causes the vortex flow interaction to decrease. The weak vortex interaction causes the vortex core trajectory to be close to the fuselage. This phenomenon will cause a negative pressure on the vertical fuselage wall which indicates energy losses that are not needed in the fuselage. While at the location of good vortex interactions (cases A0, A1, A2, B0, B1, B2) focus on the occurrence of negative pressure on the wing resulting in an effective lift force.

Similarly, with the length of the vortex core above the main wing, the influence of the canard's vortex above the wing will make the flow more stable. In cases that have good flow interactions, the vortex core above the main wing is longer and more stable. This indicates the formation of the lifting force at the larger vortex core. By looking at the results of path-line visualization of the vortex core from the side and top is obtained in the cases of $\mathrm{A} 0, \mathrm{~A} 1, \mathrm{~B} 0, \mathrm{~B} 1, \mathrm{~B} 2$, and $\mathrm{C} 0$ to produce a longer vortex core than in the other cases.

With the increasing of AoA up to $50^{\circ}$ causes the canard position close to the main wing (case A0) there will be an increase in fluctuating flow and vortex core instability. This condition causes easier vortex breakdown. The more moving forward of the location of vortex breakdown on the main wing, the resulting lift force will decrease. So that at a high attack angle the location is too close to disturb the flow and faster in the occurrence of damage to the vortex core. The best conditions for high AoA occur in a position that is a little further away (Case B0 or $\mathrm{C} 0)$.

Likewise, in Figure 7 that shows the top view of the flow formed. In the configuration of the canard position with a location closer to the main wing causes an increase in interaction. The increased interaction causes the direction of the flow of the main wing vortex core to expand outward away from the fuselage. This condition causes the concentration of negative pressure as a source of more lifting force on the outside of the wing. With the increase in AoA at $40^{\circ}$ and $50^{\circ}$, the formation of vortex nuclei is increasingly advanced and causes the concentration of negative pressure also progressing forward.

In the low AoA, the closest canard position easier to interact with the flow above the wing so that it can withstand the occurrence of the vortex breakdown. 
However, at higher AoA the location that is too close speeds up the damage of the vortex core. Likewise, for vertical positions, at the lowest AoA, the lowest position results in good flow interaction, with the highest attack angle of the canard location to the main wing resulting in a higher vortex core flow which further reduces flow interaction. The ideal configuration is in the position above and adjacent to the main wing (Cases A1, A2, B2) for low and medium AoA. Whereas for high AoA, the ideal position is in the parallel and front position of the wing (Case $\mathrm{C} 0, \mathrm{~B} 0, \mathrm{~B} 2$ ).

At low angles of attack, the canard position with a location adjacent to the main wing will give a low trajectory and widens out over the main wing. This condition will provide maximum value in generating lift and reduce the negative pressure on the fuselage vertical wall. The vortex core is formed up to the back of the wing for all configurations. At the front end of the wing, there begins to be a considerable difference in pressure distribution between the top and bottom of the wing, then shrinks along with the location that is increasingly distant from the leading edge. Whereas in the high AoA, the canard position parallel to the main wing produces a lower trajectory approaching the main wing. The lower the path of the vortex core causes the flow to maintain lift. While at the canard location which is closest (coinciding) to the main wing causes flow disruption so that faster flow damage can occur which is characterized by fluctuating flow paths that occur. So that in the high AoA condition the best trajectory happens in the configuration of the canard position with the location parallel to the main wing with a distance of $1 / 2$ canard chord in front of the main wing of the aircraft.

The canard configuration above the wing tends to produce a significant pressure difference on the front of the wing, but rapidly decreases the pressure difference on the back of the wing. While the configuration of the canard position approaches the main wing, the lateral position is better able to withstand the pressure difference to the rear of the wing, although the difference in pressure is not as large as the canard position above the wing. This canard position configuration character also applies to different AoA values.

The increase in AoA value causes an increase in the amount of pressure difference, especially on the front of the wing. This shows an increase in the strength of the vortex core in forming lift on the front of the wing. However, an increase in AoA causes pressure fluctuations especially on the back of the wing to occur more quickly as shown in Figure 11.e-f, h-i. In the figures show the location of $\mathrm{x} / \mathrm{L}=43 \%$ and $60 \%$ many canard configurations that experience pressure fluctuations due to the addition of AoA. It can be shown that the higher the AoA causes the vortex breakdown location to progress.

The canard position configuration at the top of the main wing produces a good lift force at low attack angles. While with the increase in AoA values the canard 
position further down until parallel to the main wing can maintain lift. The position of the canard far apart from the main wing reduces the level of vortex wing-canard interaction. While at a distance closer to the main wing can provide good flow interaction, especially at low attack angles. At higher attack angles (AoA $>40^{\circ}$ ), the flow interaction in the canard configuration coincides (case A0) becomes disrupted so that the forward canard position configuration (case $\mathrm{B}$ or $\mathrm{C}$ ) will give better results. The canard position slightly in front of and above the main wing (case B2) can maintain the stability of the vortex core until the angle of attack is high and the position of the back of the main wing.

\section{Conclusion}

The results of the analysis of all tests found that the addition of canard will be able to increase the lift coefficient up to $12 \%$. The canard position on the main wing affects the interaction of vortex flow, lift coefficient value, and maximum AoA. On the canard position above the main wing gives a good lift force at low attack angles, while at higher AoA the canard parallel to the main wing is better able to withstand the lifting force before the vortex breakdown.

The canard position which is far from the main wing does not provide a useful contribution in maintaining the stability of the vortex core, while the close (coincident) position with the main wing can only produce good flow interaction at low AoA. The most optimal results in all AoA conditions are obtained in the canard position above and front (Case B2). While at the high AoA, canard configuration in front of the main wing (Case $\mathrm{C} 0$ ) also gives good results. In the canard position on the top and front of the main wing gives the best value for the shift in the maximum $\mathrm{Cl}$ value between 5-10 degrees which indicates stall delay. 


\section{Nomenclature}

$$
\begin{array}{ll}
\alpha & =\text { angle of attacks (AoA/deg) } \\
\mathrm{c}_{\mathrm{c}} & =\text { canard chord length }(\mathrm{mm}) \\
\mathrm{H} & =\text { canard horizontal distance }(\mathrm{mm}) \\
\mathrm{L} & =\text { wing length }(\mathrm{mm}) \\
\mathrm{t}_{\mathrm{c}} & =\text { canard thickness }(\mathrm{mm}) \\
\mathrm{V} & =\text { canard vertical distance }(\mathrm{mm}) \\
\mathrm{y}^{+} & =\text {dimensionless wall distance } \\
\mathrm{C}_{\mathrm{L}} & =\text { lift coefficient } \\
\mathrm{C}_{\mathrm{p}} & =\text { pressure coefficient } \\
\mathrm{P} & =\text { total pressure loss }(\mathrm{Pa}) \\
\mathrm{mac} & =\text { mean aerodynamic chord } \\
\mathrm{U}_{\infty} & =\text { free stream velocity }(\mathrm{m} / \mathrm{s}) \\
\mathrm{VBL} & =\text { vortex breakdown location } \\
\mathrm{x} & =\text { axial axis } \\
\mathrm{x} / \mathrm{L} & =\text { nondimensional location at axial axis } \\
\mathrm{Y} & =\text { spanwise axis } \\
\mathrm{Z} & =\text { the model aircraft hight }(\mathrm{mm})
\end{array}
$$




\section{References}

Ali, Z. M., Kuntjoro, W., \& Wisnoe, W. (2012). Effect of canard to the aerodynamic characteristics of blended wing body airplane. Paper presented to the 2012 IEEE Symposium on Business, Engineering and Industrial Applications (Vol. 1, pp. 696-700). doi: 10.1109/ISBEIA.2012.6422979

Ali, Z. M., Kuntjoro, W., \& Wisnoe, W. (2013). The effect of canard on aerodynamics of blended wing body. Applied Mechanics and Materials, 7(5), 912-916. https://doi.org/10.4028/www.scientific.net/AMM.110116.4156

Anand S. R. \& Kulkarni, P. S. (2014). Aerodynamic performance of the canard wing configuration-A CFD Study. In 16th Annual CFD Symposium.

Cai, J. S., Cui, Y. D., \& Tsai, H. M. (2007). A combined experimental and analytical investigation of the vortex stability over sharp-edged slender bodies. Physics of Fluids, 19, 1-14. https://doi.org/10.1063/1.2766739

Cobleigh, B. R., \& Delfrate, J. (1994). Water tunnel flow visualization study of a $4.4 \%$ scale $X-31$ forebody. Retrieved from https://www.nasa.gov/centers/ dryden/pdf/88336main_H-1997.pdf

Crane, D. (2012). Dictionary of aeronautical terms (5th ed.). Newcaste, WA: Aviation Supplies \& Academics.

Davari, A. R., Hadidoolabi, M., Soltani, M. R., \& Izadkhah, M. (2015). Aspects of canard-wing vortices interaction in subsonic Flow. SCIENTIA IRANICA, 22(3), 743-755.

Desharnais, O. (2014). Aircraft conceptual design study of the canard and threesurface unconventional configurations for the purposes of reducing environmental impacts. École de technologie supérieure (Masters thesis). Retrieved from http://adsabs.harvard.edu/abs/2014PhDT.......166D. (No. AAT 1570787

Erickson, G. (1982). Water-tunnel studies of leading-edge vortices. Journal of Aircraft, 19(6), 442-448. https://doi.org/10.2514/3.57414

Erm, L. P., \& Ol, M. V. (2012). An assessment of the usefulness of water tunnels for aerodynamic investigations (AR Number AR-015-530 No. DSTO-TR2803, Air Vehicles Division DSTO Defence Science and Technology Organisation). Retrieved from http://dspace.dsto.defence.gov.au/dspace/

Firmansyah, R. D., Wibowo, S. B., \& Mareta, R. (2017). The application of measurement instrument of three degrees of freedom of aerodynamic force in 
water tunnel. Jurnal Sains Dan Teknologi, 6(2), Universitas Pendidikan Ganesha (in Indonesian).

Frate, J. H. Del. (1995). NASA Dryden flow visualization facility (No. H-1972, NASA Dryden Flight Research Center). Edwards AFB, CA: NASA Technical Memorandum.

Frink, N. T., E. Lamar, J., Lamar, J. E., Cowley, J., \& Gouws, T. (1980). Watertunnel and analytical investigation of the effect of strake design variables on strake vortex breakdown characteristic. Langely, VA: NASA. Retrieved from https://ntrs.nasa.gov/archive/nasa/casi.ntrs.nasa.gov/19800019803.pdf

Jaroszewicz, A., Stachow, J., Sibilski, K., \& Zyluk, A. (2011). Water tunnel experimental studies of leading edge vortex control on delta wing MAV. In 49th AIAA Aerospace Sciences Meeting including the New Horizons Forum and Aerospace Exposition (pp. 1-11). https://doi.org/10.2514/6.2011-1158

Jindeog, C., Tahwan, C., J, L., \& Bongzoo, S. (2002). Wind tunnel test of a canard airplane. KSME International Journal, 16(I), 125-131.

Kerho, M. (2007). Ultra low reynolds number airfoil testing facility. In 45th AIAA Aerospace Sciences Meeting (pp. 1-13). American Institute of Aeronautics and Astronautics, Inc. Retrieved from http://www.rollinghillsresearch.com/ Aero_Research/Files/AIAA-2007-0959_Low_RN_Airfoil_Testing.pdf

Kim, C. H. (1991). Flow visualization studies of a sideslipping, canardconfigured X-31A-like fighter aircraft model. Monterey, CA: Naval Postgraduate School.

Lopes, V. M. L., \& da Mota Girardi, R. (2005). Analysis of the aerodynamics characteristics of a wing-canard configuration with canard deflection using panel method. In Proceedings of COBEM 2005, 18th International Congress of Mechanical Engineering. Ouro Preto, MG: ABCM.

Manshadi, M. D., Sharafi, A., \& Soltani, M. R. (2012). An experimental investigation of the effects of canard position on the aerodynamic forces of a fighter configuration model. Journal of Aerospace Science \& Technology, 9(2), 15-23. 9. Retrieved from http://jast.ias.ir/ article_51618_ c939fafe9f8c09dd0b9903645827d341.pdf

Nasir, R. E. M., Kuntjoro, W., \& Wisnoe, W. (2014). Aerodynamic, stability and flying quality evaluation on a small blended wing-body aircraft with canard foreplanes. Procedia Technology, 15, 783-791. https://doi.org/10.1016/ j.protcy.2014.09.051 
Polhamus, E. C. (1966). Vortex lift research: Early contributions and some current challenges. In J. F. Campbell, R. F. Osborn, \& J. Foughner, J. T. (Eds.), Vortex flow aerodynamics (Vol. 1, pp. 1-30). Hampton, VA: NASACP-2416-VOL-1, L-16117, NAS 1.55:2416-VOL-1.

Polhamus, E. C. (1966). A concept of the vortex lift of sharp-edge delta wings based on a leading-edge-suction analogy (NASA technical note D-3767 No. NASA TN D-3767). NASA Technical Note (Vol. TN-D-3767). Washington, D.C. : National Aeronautics and Space Administration. Retrieved from https://ntrs.nasa.gov/archive/ nasa/ casi.ntrs.nasa.gov/19670003842.pdf

Reduan, N. F., Wisnoe, W., Kuntjoro, W., Nasir, R. E. M., Mohamad, F., \& Ali, Z. (2010). Aerodynamics characteristic of UiTM's BWB UAV Baseline-II at different canard deflection angles at low pitching angle. CSSR 2010 - 2010 International Conference on Science and Social Research, (CSSR), 10051009.

Rizzi, A. (2011). Modeling and simulating aircraft stability and control - The SimSAC project. Progress in Aerospace Sciences, 47(8), 573-588. https://doi.org/10.1016/j.paerosci.2011.08.004

Sandlin, D. R., \& Ramirez, E. J. (1991). Water tunnel flow visualization study of the vortex flow structures on the F/A-18 aircraft (No. NASA-CR-186938, NAS 1.26:186938). Retrieved from https://ntrs.nasa.gov/archive/ nasa/ casi.ntrs.nasa.gov/19910017812.pdf

Sohn, M. H., Lee, K. Y., \& Chang, J. W. (2004). Vortex flow visualization of a yawed delta wing with leading edge extension. Journal of Aircraft, 41(2), 231-237. https://doi.org/10.2514/1.9281

Sohn, M. H., Lee, K. Y., \& Chang, J. W. (2008). Delta-wing vortex visualization using micro-sized water droplets generated by an ultrasonic humidifier. Journal of Visualization, 11(4), 337-346. https://doi.org/10.1007/ BF03182202

Sutrisno, Rochmat, T. A., Wibowo, S. B., Iswahyudi, S., Wiratama, C., \& Kartika, W. (2018). The flow visualization CFD studies of the fuselage and rolled-up vortex effects of the Chengdu J-10-like fighter canard. Modern Applied Science, 12(2), 148. https://doi.org/10.5539/mas.v12n2p148

Thompson, D. H. (1990). Water tunnel flow visualisation of vortex breakdown over the F/A-18 (AR-005-007 No. DST 88/034, Defence Science And Technology Organisation Aeronautical Research Laboratory). Melbourne, Victoria: Department of Defense. 
Wibowo, S. B., \& Basuki, B. (2014). Numerical study of canard effect on aerodynamic characteristics of drone unmanned aerial vehicle. In S. V. Ugm (Ed.), Seminar Nasional Teknologi Terapan (p. 11-15 (in Indonesian)). Yogyakarta, Indonesia: ISBN 978-602-1159-06-4.

Wibowo, S. B., Sutrisno, \& Rohmat, T. A. (in press). Study of mesh independence on the computational model of the roll-up vortex phenomena on fighter and delta wing model. International Journal of Fluid Mechanics Research.

Wibowo, S. B., Sutrisno, \& Rohmat, T. A. (2018). An evaluation of turbulence model for vortex breakdown detection over delta wing. Archive of Mechanical Engineering, LXV(3), 399-415. https://doi.org/10.24425/124489

Wibowo, S. B., Sutrisno, Rohmat, T. A., Anwar, Z., Syadi, F. R., Mahardika, R., \& Naufal, W. F. (2018). An investigation into the use of GAMA water tunnel for visualization of vortex breakdown on the delta wing. In 9th International Conference on Thermofluids (p. 050007). Yogyakarta, Indonesia: AIP Conference Proceedings. https://doi.org/10.1063/1.5049998 